\title{
How does forgiveness therapy versus emotion-focused therapy reduce violent behavior schizophrenia post restrain at East Java, Indonesia?
}

\author{
Muhammad Suhron ${ }^{1}$, Ah.Yusuf ${ }^{2}$, Rika Subarniati $^{3}$, Faisal Amir ${ }^{4}$, Zakkiyatus Zainiyah ${ }^{5}$ \\ ${ }^{1,4}$ Nursing Study Program, Institute of Health Science, Ngudia Husada Madura, Indonesia \\ ${ }^{2}$ Faculty of Nursing, Universitas Airlangga, Indonesia \\ ${ }^{1,3}$ Faculty of Publich Health, Universitas Airlangga, Indonesia \\ ${ }^{5}$ Professional Midwife Study Programs, Institute of Health Science, Ngudia Husada Madura, Indonesia
}

\section{Article Info}

Article history:

Received Jun 20, 2020

Revised Aug 22, 2020

Accepted Sep 15, 2020

\section{Keywords:}

Emotion-focused therapy

Forgiveness therapy

Schizophrenia

Violent behavior

\begin{abstract}
Based on the violent behavior, the data obtained in the last 6 months using population of psychiatric inpatients with violent behavior of 64 patients. The purpose of this study was to analyze the effect of forgiveness therapy that focused on emotions of violent behavior in post restrain schizophrenia. This research method used a Quasi-experimental design. The independent variable was forgiveness therapy that focused on emotions. The dependent variable was violent behavior. The populations were 64 patients with violent behavior using a simple random sampling technique and for the sample were 52 patients. Collecting data using general adaptive function response score (GAFR) observation sheets with Wilcoxon and Mann Whitney statistical tests. Wilcoxon test showed (p-value 0.002) after being given forgiveness therapy. The Wilcoxon test showed (p-value 0.513) after being given therapy that focused on emotions it can be concluded that there are differences in violent behavior before and after therapy of forgiveness and therapy that focused on emotions. Mann Whitney test results obtained (p-value 0.016) remission therapy was more effective in reducing the violent behavior of post restrain schizophrenia.
\end{abstract}

This is an open access article under the CC BY-SA license.

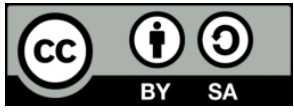

\section{Corresponding Author:}

Muhammad Suhron,

Department of Nursing,

Ngudia Husada Madura Health Institute,

Jl. RE Martadinata, No 45, Bangkalan, East Java, Indonesia.

Email: dsuhron@yahoo.co.id

\section{INTRODUCTION}

Violent behavior is a condition that a person shows actions that can be carried out using things physically on others or others with uncontrolled amok and rowdy who are uncontrolled [1]. One of response faced by someone to the stressors. This response can be detrimental to yourself, other people also the environment. Look at the losses from that have caused. Then, it is needed good treatment for the client with protection to be done quickly and precisely by professional nurses [2].

Mental health is still one of the significant health problems in the world, including in Indonesia. Based on WHO data, there are two traditional ways to study the relationship of mental illness (including schizophrenia) among to criminality generally and to violence behaviour schizophrenia post restrain like offences, persons exhibiting confusion, withdrawal, paranoia, inappropriate or bizarre speech/behavior and self-destructive tendencies that had a significantly higher probability of being arrested 
than those who did not show such signs in particular. The first one consists of the frequency examination of mental illness in persons with criminal history; the second, in the frequency examination of the criminal behavior in samples of mental patients. In the last time, two other methods used to study the relationships between mental illness and criminality have been introduced: study of community samples and study of birth cohorts [3]. It is estimated that around 35 million people died. The 60 million people died of bipolar disorder, 21 million people infected by schizophrenia, and 47.5 million approved by dementia. In Indonesia with a variety and decline in human productivity for long term. Based on Indonesian data, showing that the number of people with mental disorders increased. Where the prevalence of severe mental disorders reached $1.7 \%$ [4]. Based on data from the East Java social service, mental disorders sufferers in East Java province in 2015 were 1,619 people and the biggest sufferers in the district of Sambat Ponorogo. Whereas in 2016 it is estimated to increase to 2,369 people with schizophrenia [5].

Data of the last six months of patients with $60 \%$ of the previous patients were 78 patients [6]. One of solution to overcome the problem that can be done by forgiveness programs promote the psychological health of adolescent and adult populations who have experienced interpersonal hurt or violence. Almost all experimental studies have assessed the effects of forgiveness interventions on domains of health such as psychological functioning and mental health problems such as violence, anxiety, or stress. Forgiveness therapy reduces common mental health problems such as violence troughly promotes positive emotion, stress, and distress. Another case to reduce violence in contrast to prior study found that an emotion-focused cognitive behaviour therapy program was effective in decreasing emotion dysregulation, but not in improving adaptive emotion regulation. It can be influence to violence behaviour [7]. Emotion-focused therapy is seen as curative by serving an affect-regulation function, which is internalized over time by the client. The purpose of the research was as comparation effectively between forgiveness therapy versus emotion-focused therapy to reduce violent behavior schizophrenia post restrain. This function is accomplished by offering a soothing affect-attuned bond characterized by the therapist's presence and empathic attunement to affect as well as acceptance and congruence. Motivation factors were predisposing factors which consisting of psychological factors. Biological and social factors as well as factors that support the client and the environment [7], psychology, social, and spiritual for the victims and also affects the family and community system. Events that reflect acts of violence such as murder, unrest, combustion, beatings and torture $[8,9]$.

\section{RESEARCH METHOD}

The population of this studywas 64 patients with violent behavior however only 52 of them were chosen as respondent. One of the trial was assigned to clients who meet the criteria for violent behavior. Therapy is offered with no charge. Participants must consent to study conditions conducted, including the audio/video recording of the sessions, for participation in this study using a simple random sampling technique. Collecting data using general adaptive function respone score (GAFR) observation sheets a violent behavior such as: thoughts, feelings and actions. With score Intensive Domain I (1-10), Intensive II (11-20), Intensive III (21-30). Accordingly, the sample size estimated in this study was 0.05 with a power of 0.80 and a small effect size of 0.25 with a sample size of 52 posts restrain schizophrenia. Inclusion Criteria: schizophrenia post-restrain, violent behavior, suffer from disease more than 2 months, families who live at home environment, ages 17-65 years, Exclusion Criteria: members who care for, suffer from severe mental disorders. The emotion-focused therapy (EFT), participants must consent to the study conditions, including audio/video recording of sessions (later used for the secondary process, process-outcome, case study, and qualitative research) and attendance at pretherapy, post-therapy and 1-month follow-up evaluation sessions.

The EFT model uses specific case conceptual frameworks that postulate rather than avoid emotional experiences or emotional processes (CBT), clients struggle to overcome perform specifically that require help, disordered, detailed information about them, such as sadness/reaction, shame, and fear/main violence. The research design used in this study was the Quasy Experiment using the pretest-posttest with control group design, to control for confounding variables by homogenizing patients, namely patients with schizophrenia symptoms for less than one year, engaging in violent behavior for less than 3 weeks, taking regular medication, and scheduling routine control to health services. This cause is then activated by the client (one of the most worrying, by preventing emotions and behavior). The client seeks to overcome his feelings that need to be overcome through negative and self-care in the context of this trigger. The facts, contrary to the mainstream CBT theory, further argued that change will not be facilitated by the emotional habitude of difficult stimulation, necessary by restructuring and transforming difficult transitions through emotional processing stages forgiveness therapy uses four-phase procedures such as uncovering the anger phase; phase decides to forgive (deciding to forgive); phase forgiving (working on forgiveness); phase discovery and release from emotional prison with Wilcoxon and Mann Whitney statistical tests. 
This study was approved by the institutional review board of Ethical Approval (340/KEPK/STIKES-NHM/EC/XII/2019). The research received a certificate from the Stikes Ngudia Husada Madura ethical permission.

\section{RESULTS AND DISCUSSION}

\subsection{Demographic data}

Distribution of Participant socio-demographic characteristics of violence behavior of patients post-schizophrenic restrain in study subjects of secondary gender, smoker, age, marital status, illnes length, work, education, residences, patient relationship. The result details can be seen in Table 1.

Demographic data from the sample show that most of them were male $(n=38 ; 73 \%)$. The average age guard was 33.2 years and lived in one house 25.4 years. Most marital statuses were married $(n=31 ; 60 \%)$ the average duration of 1.5 years. Majority of them are unemployed $(n=33 ; 63 \%)$. Mostly their education were elementary school $(n=27 ; 52 \%)$. The majority of their residences are rural $(n=36 ; 70 \%)$ and most relationships were old $(n=2 ; 24 \%)$.

Table 1. Participant socio-demographic characteristics $(n=52)$

\begin{tabular}{cc}
\hline Family Characteristics & $\mathrm{n}=\%$ \\
Gender & $38(73)$ \\
Male & $14(27)$ \\
Female & \\
Smoker & $38(73)$ \\
Male & $14(27)$ \\
Female & \\
Age (M) & 33.20 years \\
Caregiver & 25.40 years \\
Living in one house & \\
Marital status & $21(40)$ \\
Divorced / unmarried / widowed & $31(60)$ \\
Married & 1.2 years of \\
Illness length (M) & \\
Work & $19(37)$ \\
Full time / part-time & $33(63)$ \\
Unemployed / retired / student & \\
Education & $27(52)$ \\
Elementary school & $14(27)$ \\
Middle school & $11(21)$ \\
High school & \\
Residences & $16(30)$ \\
Urban & $36(70)$ \\
Rural & $12(23)$ \\
Couples & $22(42)$ \\
Parents & $11(21)$ \\
Children & $7(14)$ \\
Sibling &
\end{tabular}

\subsection{Effects of amnesty therapy and emotion-focused therapy}

Table 2 shows result analysis of the effect of forgiveness therapy and emotion-focused therapeutic. The results presented that sensing therapy was more effective in reducing the violent behavior of post restrain schizophrenia compared to therapies that focused on emotions. In phase 4, this phase was the next, decided phase, the work phase and the inland phase. Researchers decided that therapy reduces the effects of aggression, restoring disputes, reducing heartache and low self-esteem [10].

Table 2. Analysis of the effect of forgiveness therapy and emotion-focused therapeutic

\begin{tabular}{cccccc}
\hline Group & Observation (Mean \pm SD) & Positive ranks & Negative ranks & Bond & p-value \\
\hline Pre-forgiveness therapy & $\pm 15.655,507$ & 4 & 15 & 4 & $0.002^{\mathrm{a}}$ \\
Post-forgiveness & $\pm 4,80010.70$ & & & & \\
Pre-emotion-focused therapy & \pm 5.28714 .96 & 5 & 3 & & $0.513^{\mathrm{b}}$ \\
Post-emotion-focused & $15.17 \pm 5.297$ & & & \\
Means Delta ( $\Delta)$ & 4.96 & & $0.016^{\mathrm{b}}$ & & \\
Forgiveness & -0.22 & & & & \\
Emotion-focused therapy & & & & & \\
\hline
\end{tabular}

$\mathrm{a}=$ Wilcoxon Test, $\mathrm{b}=$ Independent $\mathrm{t}$-test

Int. J. Public Health Sci, Vol. 9, No. 4, December 2020: 314 - 319 
Forgiveness therapy can support individuals to change negative relationships into positive ones. Individuals who had forgiveness can also change negative thoughts that are changed into better thoughts as well as individuals who can establish good relationships with others because that person has been injured. While therapy that focuses on emotion requires strong trust between therapist and client, this was usual therapy' concern because the therapist must build trust in relationships as an important prerequisite for improving self-reflection and feelings intended to the client, and related to emotional changes are focused therapy, therapists need to pay attention on different client preferences and utilize the potential when shifting to change motivation and overcome difficulties in post restrain schizophrenia. Participants who smoke can also reduce their violent behavior because it has a relaxing effect [11]. These results were also consistent on emotionally oriented on counseling, which showed that emotions are an important aspect of self-development, and are central to self-determination [12]. Emotion focused therapy aims to improve emotional coping by promoting awareness, acceptance, and a sense of people's emotional experiences [13]. The fact shown that emotional forgiveness give an effect on attribution thus supports the idea that emotions are the root of increased behavior, awareness, and feelings in care and therapy. Provided emotions are a type of adaptive readiness for processing information and actions that encourage people to their environment and improve their well-being [14].

The theory of evolution showed that forgiveness, after suffering interpersonal damage, serves to restore a beneficial relationship. It seems to be adaptive in being able to restore positive relations with principals, and change one's attitude towards them [15]. The injured people seem to make attributions of blame for the violation. For example, when people placed in victim circumstance are more likely to describe the crime as negative, intentional, and evil [16]. However, it did not seem necessary to hold offenders solely responsible for violations while trying to restore a successful partnership. Forgiveness has been shown in various programs and treatments to dramatically improve well-being [17]. The relationship between forgiveness and executive function (EF) were less well known and needs to be explored further. Similar to previous studies in undergraduate students [18], our results presented that forgiveness is very important to explain variations in EF. Evolutionary studies have shown that the prefrontal cortex, which was an area of the brain that holds EF, correlates with more caring and less punitive behavior that may be caused by improved mind theory [19].

Forgiveness is one of the therapeutic choices that can heal conflicts, both personal and in groups or communities [20]. This can be done by making the patient calm and relax. This can occur when forgiving the surrounding conditions and it requires experience and practice in self [21, 22]. From this study that forgiveness training conducted on adolescents succeeded in increasing happiness and life experiences [23, 24]. Negative experiences felt by patients become stressful which discusses the challenges around them [25, 26]. It was emphasized that forgiveness therapy can reduce liver pain because forgiveness therapy can reduce the negative effects that make the heartache to recover which requires stimulation that can improve conditions such as mania $[27,28]$. Strengthened by other researchers that found forgiveness therapy can also be in this finding, then shows that forgiveness was very important in reducing the effects of depression that leads to you and others [29], other studies found that forgiveness therapy can improve the psychological well-being violence victims of families in the household [30, 31]. Strengthen other research that forgiving ranking interpersonal real-life violations can be a significant determinant of psychological well-being, especially among religious/interested communities and spiritual population [32, 33].

Meanwhile forgiveness has been shown significantly can improve health and well-being in many interventions and therapies [34]. Besides, the positive effects of forgiveness on attribution can pave the way for further steps in engagement relationships, some authors have questioned the benefits of forgiveness by revealing what is meant by increased forgiveness and reinforcement $[35,36]$. In other cases, reporting about women living in shelters of domestic violence is more likely to form an intention to return their compilation partners more forgiveness and thus reporting forgiveness can help which increases in this case between forgiveness and negative outcomes moderated by contextual variables that are urgent. Specifically, find out forgiveness is only associated with less relationship satisfaction and more serious problems with more negative partners.

Forgiveness is associated with greater relationship satisfaction and fewer problems in less difficult relationships [37]. Following other results, forgiveness results in negative relationship with your partner's self-esteem, unpleasant, or does not make amends, but forgiveness is related to better yourself, self-support, or making improvements [38]. Thus, while this research showed that forgiveness has a positive impact on individual attributions to offenders, the question of whether forgiveness provides positive discussion results is highly dependent on the severity and the context in which what happened was proven. In line with contextual considerations and discussions with severity stalled, this study enhances the effects of emotional forgiveness and decisions on individual changes in attribution. Found forgiveness can reduce negative feelings, reduce depression, and improve physiological health status. Emotional forgiveness can 
replace positive emotions with negative emotions. Emotional forgiveness can also change psych physiologists more positively about people's health and well-being [38, 39]. Another study explained that the positive association revealed the empathic performance and metacognitive self-reflectivity, across emotions. Realistic forgiveness in such environment does have beneficial interests for the individual [39].

\section{CONCLUSION}

Forgiveness therapy was more effective in reducing the violent behavior of schizophrenia rather than therapies that focus on emotion. Forgiveness therapy can support individuals to change their logics to be positive in post-restrain schizophrenia patients in East Java, Indonesia. Forgiveness in such environment also has beneficial interests for the individual.

Forgiveness therapy change negative relationship with partner's self-esteem, unpleasant, or make amends a positive relationship to be better, self-support, or making improvement. Limitation of this study was small sample size. For the future research, the sample size should be enlarger for more comprehensive results.

\section{REFERENCES}

[1] Yiwei Xia, et al. "The Interrelationship between Family Violence, Adolescent Violence, and Adolescent Violent Victimization: An Application and Extension of the Cultural Spillover Theory in China," Int J Environ Res Public Health., vol. 15, no. 2, pp. 371, 2018.

[2] Short, J., "Thinking differently: Re-framing family violence responsiveness in the mental health and addictions health care context," Int J Ment Health Nurs., vol. 28 no. 5, pp. 1209-1219, 2019.

[3] WHO., World Health Organization 2019: Mental Health, New Understanding, New Hope. Geneva: Health World Organization, 2019 [Online]. Available: https://www.who.int/news-room/fact-sheets/detail/schizophrenia

[4] Ministry of Health Republic of Indonesia, Basic Health Research. Jakarta: Health Research and Development Agency Ministry of Health Republic of Indonesia, 2018. [Online]. Available: https://kesmas.kemkes.go.id/assets/upload/dir_519d41d8cd98f00/files/Hasil-riskesdas-2018_1274.pdf

[5] East Java Province Social Service., Free Pasung 2019 with e-Pasung Program as an Effort to Succeed Pasung Program, Surabaya: East Java Province Social Service, 2018. [Online]. Available: http://kominfo.jatimprov.go.id/read/umum/gubernur-penanganan-program-bebas-pasung-di-jatim-masih-terus-berjalan .

[6] Bangkalan Social Service. Program E-Pasung: Bangkalan Social Service, 2018. [Online]. Available: http://www.bangkalankab.go.id/v5/dat_berita.php?nart=1409/Tahun_Ini,_Pemkab_Bangkalan_Targetkan_Bebas_Pasung

[7] Yosep, Iyus., "Psychiatric Nursing," Bandung: PT. Refika Aditama, 2010.

[8] Prabowo., "Concepts \& Applications of Psychiatric Nursing," Yogyakarta: Nuha Medika, 2014.

[9] Nashori, HF., "Forgiveness of Ethnic Students Judging from the Orientation of Javanese Cultural Values, Trait Personality, and Demographic Factors," Research Report, Yogyakarta: DPPM UII. 2012.

[10] Suhron, M., "Care of Mental Nursing the Concept of Self-Esteem (Asuhan keperawatan jiwa konsep self esteem)," Jakarta: Mitra Wacana Media, 2017.

[11] Torres S., et al., "Emotion-Focused Cognitive Behavioral Therapy in Comorbid Obesity with Binge Eating Disorder: A Pilot Study of Feasibility and Long-Term Outcomes," Front Psychol., vol. 11, no. 7, pp. 343, 2020.

[12] Timulak L., "Emotion-focused therapy as a transdiagnostic treatment for depression, anxiety and related disorders: Protocol for an initial feasibility randomised control trial," Version 1. HRB Open Res., vol. 3, no. 7, pp. 5-11 2020.

[13] Greenberg, LS., "Paivio SC Working with Emotions in Psychotherapy," New York, NY: Guilford Press, 1997.

[14] Frijda, NH., "The Emotions," Cambridge: Cambridge University Press, 1986.

[15] McCullough, ME., "Beyond Revenge: Evolution of the Forgiveness Instinct," San Francisco, CA: Jossey-Bass, 2008.

[16] Exline, JJ, et al., "Express forgiveness and repentance: Benefits and obstacles," In M. McCullough, K. Pargament, $\&$ C. Thoresen (Eds.), Forgiveness, pp. 133-155, New York: Guilford. 2000.

[17] Raj, M., et al., "Barriers to forgiveness," Soc. Pers. Psychol. Compass., vol. 10, no. 2, pp. 679-690, 2016.

[18] Kruger HJ., "Functions and positive psychological characteristics: A replication and extension," Articles in Psychological Reports., vol. 108, no. 2, pp. 477-86, 2011.

[19] Billingsley, J., et al., "The Forgiveness Nervous System: An Evolutionary Psychological Perspective," Front Psychol., vol. 8, no. 2, pp. 737, 2017.

[20] Robert J. Murray. "Forgiveness as a Therapeutic Option," The Family Journal, vol. 10, no. 3, pp. 315-321, 2002.

[21] Suhron, M., F Amir. "Reducing Schizophrenia of Violent Behavior: A New Approach Using LT (Laughter Therapy) And DRT (Deep Relaxation Therapy)," Indian Journal for Public Health Research \& Development., vol. 9, no. 8, pp. 1518-1523, 2018.

[22] Suhron M., "Self-concept nursing care: Self esteem (Asuhan keperawatan konsep diri: Self-esteem)," Publisher, Ponorogo: Unmuh Ponorogo Press, 2016.

[23] Suhron, M., "Model of Potential Strengthening and Family Roles in Improving Family Members for ODGJ Adaptability, " Proceeding of The 2nd International Symposium of Public Health, vol. 1, no. 1, pp. 344-354, 2018.

[24] Sugeng, M., Yusuf, Ah., Rika, S., Suhron, M., "The Burden in Providing Caregiving Service to Mentally Illed Patients in Ponorogo," Indian Journal of Public Health Research \& Development, vol. 10, no. 10, pp. 1070-1074, 2019. 
[25] Yusuf, Ah., Rika, S., Suhron, M., “Assessment of the Kempe Family Stress Inventory in self-care post-restrain schizophrenia," International Journal of Public Health Science (IJPHS), vol. 8, no. 2, pp. 55-59, 2019.

[26] A Yusuf, M Suhron, R Subarniati, "Assessment of the Kempe Family Stress Inventory in self-care post-restrain schizophrenia," International Journal of Public Health Science (IJPHS), vol. 8, no. 2, pp. 55-59, 2019.

[27] Safaria, et al., "Emotion Management, A Smart Guide How to Manage Positive Emotions in Your Life," Jakarta: PT Bumi Aksara, p. 228, 2017.

[28] Suhron, M., A Yusuf, R Subarniati, "Assessment of Stress Reactions and Identification of Family Experiences in Primary Care Post Schizophrenic Restrain in East Java, Indonesia. Mixed Method: Sequential Explanation," Indian Journal for Public Health Research \& Development, vol. 10, no. 12, pp. 1849-1854, 2018.

[29] Hamid, AYS., "Mental Health Nursing Care," Potpourri, EGC, 2008.

[30] Minjee J., et al. "Self-Forgiveness Moderates the Effects of Depression on Suicidality," Psychiatric Investigation, vol. 16, no. 2, pp. 121-129, 2019.

[31] Long, K.NG. "Spiritually Motivated Self-Forgiveness and Divine Forgiveness, and Subsequent Health and WellBeing Among Middle-Aged Female Nurses: An Outcome-Wide Longitudinal Approach," Front Psychol., vol. 11 no. 1 , pp. $1337,2020$.

[32] Toussaint, L et al. "Effects of lifetime stress exposure on mental and physical health in young adulthood: How stress degrades and forgiveness protects health," J Health Psychol., vol. 21, no. 6, pp. 1004-1014, 2016.

[33] Akhtar, S., "Understanding the Relationship between State Forgiveness and Psychological Welfare: A Qualitative Officer," J Relig Health., vol. 56, no. 2, pp. 450-463, 2017.

[34] Mc Nulty JK., "When a positive process hurts the relationship," Curr. Dir Psychol. Sci., vol. 19, no. 2, pp. 167-171, 2010.

[35] Worthingtonal., "Review Forgiveness, health, and well-being: review of evidence for emotional forgiveness versus decision making, forgiveness of dispositions, and reduction of disobedience," J Behav Med., vol. 30, no. 4, pp. 291-302, 2007.

[36] Ascenzo, N., Collard, J., "Anger, forgiveness, and depression in postnatal experiences," Mental Health and Family Medicine Ltd., vol. 13, no. 2, pp. 689-698, 2018.

[37] Safaria, T., "Forgiveness, Gratitude, and Happiness among Professional Psychology Masters Students". International Journal of Public Health Sciences (IJPHS), vol. 3, no. 4, pp. 241-245, 2014.

[38] Lichtenfeld, S., "Effect of Decision and Emotional Forgiveness on Attributes," Psychic Home., vol. 10, no. 1425, 2019.

[39] Kelsey A.B., et al. "Emotion Specific performance of emotions across empathy tasks in schizophrenia: Effects of metacognitive capacity," Schizophr Res Cogn., vol. 19, no. 1, pp. 100139, 2020. 